\title{
Antidepressant Effect of Optogenetic Stimulation of the Medial Prefrontal Cortex
}

\author{
Herbert E. Covington III, ${ }^{1}$ Mary Kay Lobo, ${ }^{1}$ Ian Maze, ${ }^{1}$ Vincent Vialou, ${ }^{1}$ James M. Hyman, ${ }^{2}$ Samir Zaman, ${ }^{1}$ \\ Quincey LaPlant, ${ }^{1}$ Ezekiel Mouzon, ${ }^{1}$ Subroto Ghose, ${ }^{3}$ Carol A. Tamminga, ${ }^{3}$ Rachael L. Neve, ${ }^{4}$ Karl Deisseroth,${ }^{5}$ \\ and Eric J. Nestler ${ }^{1}$ \\ ${ }^{1}$ Fishberg Department of Neuroscience, Mount Sinai School of Medicine, New York, New York 10029, ${ }^{2}$ Department of Psychiatry, University of British \\ Columbia, Vancouver, British Columbia V6T 2B5, Canada, ${ }^{3}$ Department of Psychiatry, The University of Texas Southwestern Medical Center, Dallas, Texas \\ 75390, ${ }^{4}$ Department of Brain and Cognitive Sciences, Massachusetts Institute of Technology, Cambridge, Massachusetts 02139, and ${ }^{5}$ Department of \\ Bioengineering, Stanford University, Stanford, California 94305
}

Brain stimulation and imaging studies in humans have highlighted a key role for the prefrontal cortex in clinical depression; however, it remains unknown whether excitation or inhibition of prefrontal cortical neuronal activity is associated with antidepressant responses. Here, we examined cellular indicators of functional activity, including the immediate early genes (IEGs) zif268 (egr1), c-fos, and arc, in the prefrontal cortex of clinically depressed humans obtained postmortem. We also examined these genes in the ventral portion of the medial prefrontal cortex (mPFC) of mice after chronic social defeat stress, a mouse model of depression. In addition, we used viral vectors to overexpress channel rhodopsin 2 (a light-activated cation channel) in mouse mPFC to optogenetically drive "burst" patterns of cortical firing in vivo and examine the behavioral consequences. Prefrontal cortical tissue derived from clinically depressed humans displayed significant reductions in IEG expression, consistent with a deficit in neuronal activity within this brain region. Mice subjected to chronic social defeat stress exhibited similar reductions in levels of IEG expression in mPFC. Interestingly, some of these changes were not observed in defeated mice that escape the deleterious consequences of the stress, i.e., resilient animals. In those mice that expressed a strong depressive-like phenotype, i.e., susceptible animals, optogenetic stimulation of mPFC exerted potent antidepressant-like effects, without affecting general locomotor activity, anxiety-like behaviors, or social memory. These results indicate that the activity of the mPFC is a key determinant of depression-like behavior, as well as antidepressant responses.

\section{Introduction}

Altered functional activity within the medial and anterior regions of the prefrontal cortex is thought to be important for mediating key symptoms of depression (Manji et al., 2001; Keedwell et al., 2005; Krishnan and Nestler, 2008). Brain imaging studies of depressed patients have suggested both increases and decreases in cortical activity, with a notable decrease occurring in response to negative-valence stimuli, abnormalities that are restored after successful antidepressant treatment (Mayberg, 2003; Fales et al., 2008). In cases where conventional antidepressants fail, stimulation of the anterior cingulate region of prefrontal cortex can be highly effective (Mayberg et al., 2005; Nahas et al., 2010). These results support the hypothesis that aspects of human depression are mediated through prefrontal cortical mechanisms.

Received April 5, 2010; revised Sept. 7, 2010; accepted Sept. 27, 2010.

This work was supported by grants from the National Institute of Mental Health, a research alliance with AstraZeneca (E.J.N.), and a NARSAD Young Investigator Award (H.E.C.) from the National Alliance for Research on Schizophrenia and Depression. E.J.N. reports consulting income from Merck Research Laboratories and PsychoGenics, Inc

Correspondence should be addressed to Eric J. Nestler, Fishberg Department of Neuroscience, Mount Sinai School of Medicine, One Gustave L. Levy Place, Box 1065, New York, NY 10029. E-mail: eric.nestler@mssm.edu.

H. E. Covington III's present address: Department of Psychology and Neuroscience, Duke University, Durham, NC 27708.

DOI:10.1523/JNEUROSCI.1731-10.2010

Copyright $\odot 2010$ the authors $\quad$ 0270-6474/10/3016082-09\$15.00/0
Exposure of rodents to stress can modify the activity, transcriptional state, and morphological profile of neurons within the medial prefrontal cortex (mPFC) (Nikulina et al., 2004; Liston et al., 2006; Czéh et al., 2007; Radley et al., 2008; Dias-Ferreira et al., 2009). Notably, a long-lasting decrease in the functional activity of the ventral portion of the mPFC was inferred by reduced expression of the immediate early gene (IEG) zif268 (also known as egr1) following brief bouts of social defeat stress (Covington et al., 2005). These findings are consistent with the observation that $\mathrm{mPFC}$ lesions induce hyper-sensitive stress responses and deficits in fear extinction (Holson, 1986; Silva et al., 1986; Diorio et al., 1993; Milad and Quirk, 2002). Stress-induced mPFC changes in activity may therefore underlie depression-related behaviors.

Utilizing postmortem human brain tissue obtained from the medial portion of anterior cingulate cortex of clinically depressed humans, we investigated here the functional activity of this brain region, as inferred from measurements of zif268 and two other IEGs, $c$-fos and arc (Dragunow and Faull, 1989; Dragunow, 1996; Bramham et al., 2008). We also studied the ventral region of the $\mathrm{mPFC}$ of mice following chronic social defeat stress, an animal model of depression (Berton et al., 2006; Tsankova et al., 2006; Rygula et al., 2008; Covington et al., 2009). Rodent ventral mPFC, like primate anterior cingulate cortex, is critically involved in the regulation of emotional behavior (Vogt et al., 1992; Barbas, 1995; Heidbreder and Groenewegen, 2003). We examined IEG expres- 
sion to gain insight into the effect of chronic stress on cortical mechanisms in mice that exhibit the deleterious effects of stress ("susceptible" mice) or those that escape these deleterious effects ("unsusceptible" or resilient mice) (Krishnan et al., 2007). Then, to directly determine the role of prefrontal cortical activity in depressive-like behaviors, we stimulated the mPFC of susceptible mice using viral-mediated expression of channel rhodopsin 2 (ChR2), a blue-light-sensitive cation channel (Adamantidis et al., 2007; Zhang et al., 2007; Airan et al., 2009; Lobo et al., 2010). A pattern of laser stimulation was delivered to mimic cortical burst firing reported in vitro (Yang et al., 1996). We hypothesized that mPFC stimulation would generate antidepressant-like behavioral responses in susceptible mice subjected to chronic social defeat stress.

\section{Materials and Methods Experimental procedure \\ Mice}

Nine- to 10-week-old C57BL/6J male mice (Jackson Laboratories) were used for all mouse experiments. Two days before the beginning of experiments, all mice were singly housed and continued on a $12 \mathrm{~h}$ light/dark cycle with ad libitum food and water access. Behavioral assessments and tissue collection were conducted $1 \mathrm{~h}$ after the start of the animals' dark phase. Mouse procedures were conducted in accordance with the Institutional Animal Care and Use Committee guidelines of Mount Sinai School of Medicine.

\section{Behavioral assessments}

Social interaction. Social interaction was performed as described previously (Berton et al., 2006; Tsankova et al., 2006). In brief, mice were placed within a novel arena with a small animal cage located at one end. Each socially stressed or control mouse's movement was monitored for 100 s during laser stimulation that was delivered in the absence of a CD1 mouse (open field behavior), followed by $100 \mathrm{~s}$ in the presence of a CD1 (social interaction behavior). Locomotor activity measurements (distance traveled) and information pertaining to the duration spent in the confines of the interaction zone was obtained using Ethovision 3.0 software.

Sucrose preference. Tubes $(50 \mathrm{ml})$ containing stoppers fitted with ballpoint sipper tubes to prevent leakage (Ancare) were filled with solutions containing either $1 \%$ sucrose (in drinking water) or drinking water alone. All animals were acclimatized for 3 consecutive days to two-bottle choice conditions starting the day after surgery for prefrontal cortex viral infusion, before 1 additional day of choice testing (noon-noon), when experimental laser stimulation was conducted. Immediately before the $24 \mathrm{~h}$ test, fluid levels were noted and the positions of the tubes were interchanged. The blue laser was used to deliver $5 \mathrm{~min}$ of optogenetic stimulation, as described above, on two separate occasions during the dark (active) phase of the light-dark cycle. The first laser stimulation was delivered to mice $1 \mathrm{~h}$ after the onset of the dark phase and the second $6 \mathrm{~h}$ later. Sucrose preferences were calculated as the percentage of sucrose/ water consumed.

Social recognition test. Social memory was assessed during laser stimulation using a modified version of a social recognition test (Dluzen and Kreutzberg, 1993). C57BL/6J mice were surgically prepared by viral infection of ChR2-mCherry- or mCherry-expressing vectors and fixation of guide cannula over the prefrontal cortex. Three days later, experimental mice were allowed to become familiar with another C57BL/6J mouse that was 1 week younger than the experimental mouse, by placing them into this younger mouse's home cage for $30 \mathrm{~min}$ on five separate occasions, each separated by $1 \mathrm{~h}$. The following day, each experimental C57BL/6J mouse was allowed to interact with the familiar C57BL/6J mouse or a novel CD1 mouse, each located on separate ends of the arena behind a small animal cage (as described in the social interaction test) for $65 \mathrm{~s}$.

Elevated plus maze. The elevated plus maze was designed using black Plexiglas fitted with white bottom surfaces to provide contrast, and tests were conducted as previously described (Monteggia et al., 2007). C57BL/6J mice received intra-mPFC ChR2-mCherry- or mCherry- expressing vectors and guide cannula. Mice were subsequently placed in the center of the plus maze and allowed to freely explore the maze for 5 min under red-lighting conditions, while laser deliveries of blue light were directed into the mPFC in a "burst-like" manner. The position of each mouse over time in the open and closed arms was monitored with videotracking equipment (Ethovision) and a ceiling-mounted camera.

\section{Herpes simplex virus viral vectors}

Herpes simplex virus (HSV) vectors driven by the IE4/5 promoter expressing ChR2 fused to mCherry [HSV-ChR2-mCherry, in HSVPrpUC, using the ChR2-mCherry DNA construct (Airan et al., 2009), or mCherry alone (in p1005/mCherry)], were prepared as described previously (Neve et al., 2005; Lobo et al., 2010). Since HSV expression is maximal on days 3-4 postinfection, all ChR2 blue light stimulation was performed on day 4 .

\section{Optical fiber}

To control in vivo patterns of neuronal firing, a $200 \mu \mathrm{m}$ (external size) optic fiber (Thor Labs) was custom modified for attachment to the cannula. When securing the optic fiber before in vivo laser presentations, the fiber was stripped down to the $100 \mu \mathrm{m}$ core, so that when lowered through the guide cannula it became flush with the length of the guide, fixed at the dorsal edge of the prefrontal cortex (prelimbic region). This secure connection to the cannula is a slightly modified version from that used in previous studies (Gradinaru et al., 2007; Airan et al., 2009). Optical fibers were lowered and secured to each cannula head-mount assembly only during stimulation trials.

\section{Blue light stimulation}

Optical stimulations were performed similar to previously published protocols (Gradinaru et al., 2007; Airan et al., 2009). Optical fibers (Thor Labs) were connected via a FC/PC adaptor to a $473 \mathrm{~nm}$ blue laser diode (Crystal Lasers, BCL-473-050-M), and a stimulator (Agilent, \#33220A) was used to generate blue light pulses. During all stimulations, $40 \mathrm{~ms} 100$ $\mathrm{Hz}$ (9.9 ms spike width) blue light pulses (i.e., bursts) were delivered every $3 \mathrm{~s}$ to the mPFC over the duration of each behavioral test, to mimic a burst-like pattern of cortical activity (Yang et al., 1996). The intensity of the optic fiber light was verified before each use, using a light sensor (Thor Labs, S130A), and light intensity ranged from 1 to $2 \mathrm{~mW}$.

\section{Mouse MPFC tissue collection}

Bilateral punches (15 gauge) of the ventral area of the mPFC were obtained from C57BL/6J mice as previously described (Renthal et al., 2007) after 10 continuous days of chronic social defeat stress (Berton et al., 2006), or after stimulation by a blue laser, using the same stimulation conditions used for behavioral experiments. Collected tissue was immediately frozen, and stored at $-80^{\circ} \mathrm{C}$ until processing.

\section{RNA isolation, reverse transcription, and quantitative PCR}

Frozen human or mouse tissue was thawed in TriZol (Invitrogen) and processed according to the Invitrogen protocol. RNA was purified using RNeasy Micro columns (Qiagen) and processed as indicated via the Qiagen kit manual. Spectroscopy measurements were used to confirm that RNA had $A_{260 / 280}$ and $A_{260 / 230}$ ratios $>1.8$. Total RNA was reverse transcribed using an iScript kit (Bio-Rad) following the instructions provided by the manufacturer. Quantitative PCR ( $\mathrm{qPCR}$ ) was performed using $\sim 3.75 \mathrm{ng}$ of cDNA for each reaction plus primers and SYBR Green (Applied Biosystems). PCRs for zif268, arc, and c-fos were performed in triplicate, and quantified using the $\Delta \Delta \mathrm{Ct}$ method as previously described (Maze et al., 2010).

\section{c-Fos immunohistochemistry}

One hour after optical stimulation mice infected with ChR2-mCherry or mCherry alone were anesthetized and perfused intracardially with $4 \%$ paraformaldehyde/PBS. Brains were removed and postfixed by immersion overnight in $4 \%$ paraformaldehyde and cryoprotected in 30\% sucrose/PBS. Coronal sections $(30 \mu \mathrm{m})$ were cut on a freezing microtome and processed for immunohistochemistry. Sections were preincubated in a blocking buffer containing $0.3 \%$ Triton and 3\% normal donkey serum. After blocking, sections were incubated with an antibody directed against c-Fos (1:1500, Santa Cruz Biotechnology) in blocking buffer. 
After washing, sections were incubated with Cy2-conjugated secondary antibody (1:1600, Jackson Immunoresearch). Subsequently, slides were coverslipped and visualized under a microscope $(100 \times)$ for capturing images of mCherry (red fluorescence), c-Fos (green fluorescence), or both merged (see Fig. $4 A$ ).

For double immunolableing of c-Fos with CaMKII $\left(\mathrm{Ca}^{2+} /\right.$ calmodulin-dependent protein kinase II) or GABA, sections were blocked in 3\% normal donkey serum and $0.3 \%$ Triton-X in $0.1 \mathrm{M}$ PBS for $1 \mathrm{~h}$. Sections were subsequently incubated overnight in primary antibodies in the above blocking solution using the following antibodies: rabbit anti-c-Fos (1:500, Santa Cruz Biotechnology) and mouse anti-CaMKII (1:200, Millipore Bioscience Research Reagents) or mouse anti-GABA (1:1000, Sigma). The next day, sections were rinsed in $0.1 \mathrm{M}$ PBS and placed into secondary antibodies: donkey anti-rabbit-Cy3 and donkey anti-mouse-Cy2 (1:200, Jackson ImmunoResearch) in $0.1 \mathrm{~m}$ PBS for $1 \mathrm{~h}$. Sections were again rinsed in $0.1 \mathrm{M}$ PBS, mounted and coverslipped in DEPEX.

\section{Stereotaxic surgery for viral infections and guide cannula placement for optic fiber}

While under a combination of ketamine $(100 \mathrm{mg} / \mathrm{kg})$ and xylazine $(10$ $\mathrm{mg} / \mathrm{kg}$ ) anesthesia, experimental C57BL/6J mice were surgically infused with either viral vector that expresses ChR2 plus mCherry or mCherry alone (Lobo et al., 2010); vectors were targeted to the infralimbic and prelimbic regions of prefrontal cortex. Specifically, a Hamilton syringe was fitted with a 33 gauge needle and filled with $1.5 \mu \mathrm{l}$ of virus. From bregma, at the surface of the skull, the needle was lowered unilaterally at a $15^{\circ}$ angle into the prefrontal cortex [anteroposterior $(\mathrm{AP})=1.75$, mediolateral $(\mathrm{ML})=0.75$, dorsoventral $(\mathrm{DV})=2.65]$, whereupon $0.4 \mu \mathrm{l}$ of virus was delivered over $4 \mathrm{~min}$. After a $5 \mathrm{~min}$ delay, the needle was pulled up $0.25 \mathrm{~mm}$ and an additional $0.4 \mu \mathrm{l}$ of virus was delivered over 4 additional minutes. After the second infusion, the needle was left in place for $5 \mathrm{~min}$ to allow for diffusion. Immediately after the completion of viral infusions, 20 gauge stainless steel guide cannula $(2 \mathrm{~mm}$ projection from the pedestal; Plastics One) were positioned directly over the viral infusion site $(\mathrm{AP}=1.75, \mathrm{ML}=1.75, \mathrm{DV}=1.7$, from bregma $)$ above the prefrontal cortex and secured to the skull via Cerebond skull cement. All mice were allowed $3 \mathrm{~d}$ to recover from surgery before the start of optical stimulation experiments.

\section{Statistics}

Comparisons between depressed (medicated and unmedicated combined) versus control postmortem tissue were initially made for the results of RNA analyses using two tailed $t$ tests. Subsequently, isolated comparisons of RNA results between depressed (medicated or unmedicated) versus control postmortem tissue, between socially defeated (susceptible or unsusceptible) versus control tissue, were made by one-way ANOVAs. Analyses of social interaction, locomotor behavior in an open field, and sucrose preferences in control and susceptible mice expressing either ChR2-mCherry or mCherry during stimulation were analyzed by $2 \times 2$ ANOVAS (stress $\times$ virus). Significant isolated comparisons were determined via Bonferroni post hoc analyses. The comparison of social interaction behavior $24 \mathrm{~h}$ after stimulation with the laser was made using a two-tailed $t$ test. Likewise, comparisons of social recognition behavior and elevated plus maze behavior between groups of mice infected with ChR2-mCherry or mCherry were determined using two-tailed $t$ tests.

\section{Experiment 1: IEG expression in depressed human postmortem prefrontal cortical tissue}

To assess constitutive functional activity during clinical depression, human brain tissue was obtained by the Dallas Brain Collection (Stan et al., 2006). Tissue was collected after obtaining consent from the next of kin, along with permission to obtain medical records, and a direct telephone interview with a primary caregiver. For each case, blood toxicology screens were conducted and those subjects with a history of drug abuse, neurological disorders, or head injury were not included (supplemental Fig. S2, available at www.jneurosci.org as supplemental material). Medical records were examined by two psychiatrists who made independent diagnoses, which were followed by a consensus diagnosis according to
DSM IV criteria. The collection of human brain tissue was approved by the Institutional Review Board of University of Texas Southwestern Medical Center at Dallas. The tissue cohort consisted of 10 pairs of cases of depression and controls matched for age, brain $\mathrm{pH}$, postmortem interval, and RNA integrity number. Samples of the anterior division of the anterior cingulate cortex (Brodmann area 24) were removed from fresh brain specimens at the level of the rostrum of the anterior cingulate gyrus, the point at which the gyrus curves above and below the corpus callosum. Tissue samples were snap frozen and kept at $-80^{\circ} \mathrm{C}$ until processing for qPCR analysis of zif268, c-fos and arc mRNA expression. Depressed individuals that were being treated with antidepressants at the time of death were separated from those that were not; however, all subjects were symptomatically depressed at the time of death. Comparisons of each IEG were made between controls, depressed medicated, and depressed unmedicated cases, to reveal potential medication effects.

\section{Experiment 2: IEG expression in the mPFC of mice after chronic social defeat stress}

Mice were subjected to chronic ( $10 \mathrm{~d}$ ) social defeat stress as previously described (Berton et al., 2006). In brief, 96 experimental C57BL/6J mice were exposed to a novel CD1 aggressor for 5 min daily, and then separated from the aggressor behind a protective barrier, which was perforated to allow for sensory contact, for the remainder of the day, over 10 consecutive days. During bouts of physical contact, visible signs of subordination were observed including hallmark stress responses of escape, submissive posturing, and freezing. Non-defeated control mice $(n=40)$ were housed as two animals per cage under the same conditions as their experimental counterparts, but without the presence of a CD1 mouse. Immediately following the last social defeat episode, all experimental and control mice were housed individually. Twenty-four hours after the last social defeat, all stressed and control mice were assessed for social interaction. The duration (seconds) of social interaction was used as the dependent measure. The distribution of interaction scores after social defeat stress was positively skewed and therefore failed three tests for normality within a Gaussian distribution, i.e., Kolmogorov-Smirnov $(p<0.0001)$, D'Agostino and Pearson $(p<0.0001)$, and Shapiro-Wilks $(p<0.0001)$ (see supplemental Fig. S3, available at www.jneurosci.org as supplemental material), since the majority of stressed mice displayed severe social avoidance compared with those remaining socially intact, as previously observed (Krishnan et al., 2007). Thus, defeated mice were divided into two groups based on the upper 75th percentile of social interaction scores for all stressed mice $(\mathrm{MIN}=1.8 \mathrm{~s}, \mathrm{MAX}=98.1 \mathrm{~s}, 75$ th percentile $=35.4 \mathrm{~s})$. In the end effect, 72 mice were considered susceptible and 24 mice with interaction scores $>35$ s were determined to be unsusceptible (Krishnan et al., 2007). Eight mice from each of the three groups (i.e., control, susceptible, and unsusceptible) were randomly selected for expression analysis of the IEGs, zif268, c-fos and arc, in mPFC tissue collected $24 \mathrm{~h}$ after the social interaction test. An additional 36 stressed mice that were considered to be susceptible ( $<35 \mathrm{~s}$ of social interaction), as well as 32 controls, were used for subsequent assessments on the functional impact of optogenetic cortical stimulation in two behavioral tests that predict antidepressant effects (see Experiment 3 below).

\section{Experiment 3: antidepressant effects of optogenetic stimulation of the mPFC}

To assess whether or not optogenetic stimulation of the mPFC reverses social avoidance induced by chronic social defeat stress, susceptible $(n=$ $36)$ and control $(n=32)$ mice were surgically prepared within $48 \mathrm{~h}$ after the social interaction test with intra-mPFC viral infusion of ChR2mCherry (or mCherry alone as a control) and cannula placement, to later guide the direction of an optical fiber. Four days after this surgery, 20 avoidant mice ( $n=10$ ChR2-mCherry, $n=10$ mCherry) and 20 corresponding non-stressed controls were again tested for social interaction when patterns of light were delivered via a laser in a burst-like fashion ( $100 \mathrm{~Hz}$ every $3 \mathrm{~s})$. In addition, a separate cohort of 16 susceptible mice ( $n=8$ ChR2-mCherry, $n=8$ mCherry) and 12 control mice ( $n=6$ ChR2-mCherry, $n=6$ mCherry) were surgically prepared as described 
A

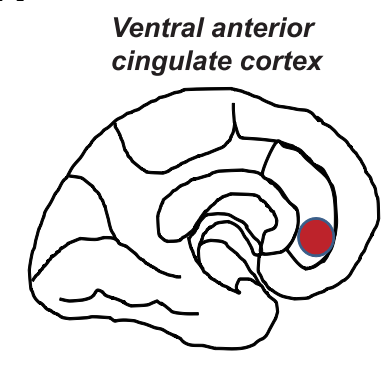

B
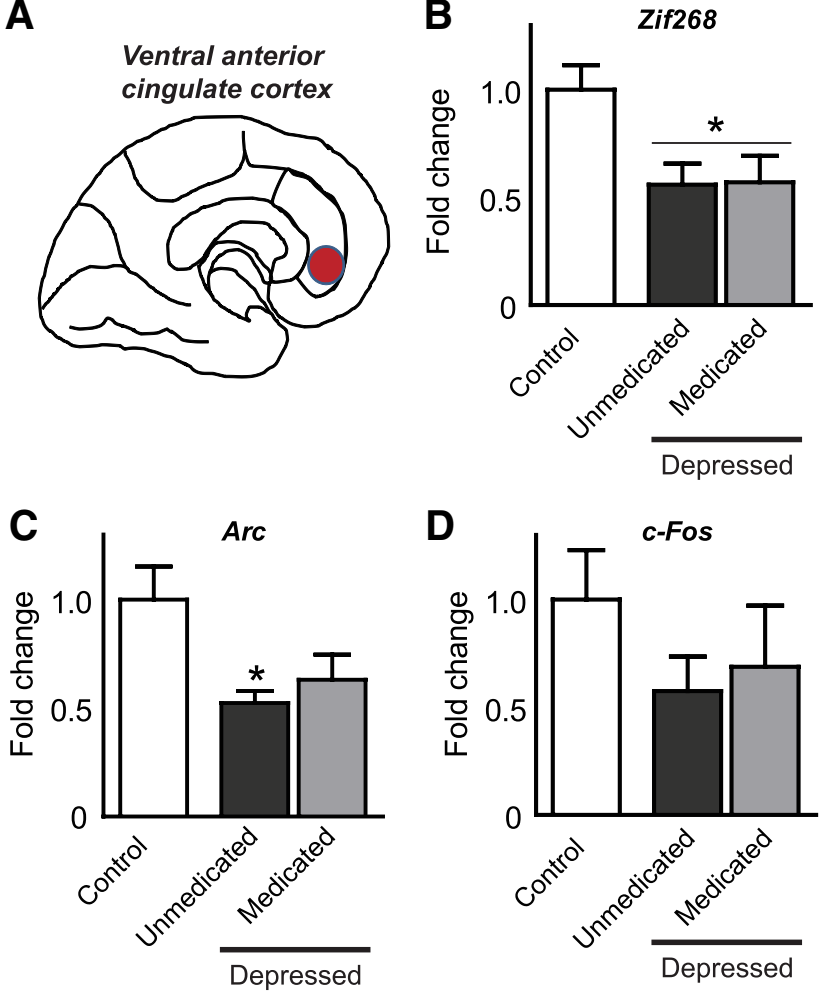

Figure 1. $A-D$, Deficits in IEG expression in the prefrontal cortex of depressed humans. zif268, arc, and c-fos mRNA expression was quantified via qPCR in tissue collected from human postmortem ventral-medial anterior cingulate cortex (A). mRNA levels of zif268 and arc, but not $c-f o s$, were reduced in this region of depressed individuals. These effects predominated in unmedicated depressed individuals, but strong trends were seen in medicated patients who remain symptomatic $(\boldsymbol{B}-\boldsymbol{D})$. Significant differences from controls are indicated by ${ }^{*} p<0.05$.

above and were examined $4 \mathrm{~d}$ later for their level of sucrose (1\%) preference over a $24 \mathrm{~h}$ test, with a burst-like pattern of optogenetic stimulation delivered for $5 \mathrm{~min}$ on two separate occasions during their dark (active) phase.

Experiment 4: assessment of social memory and anxiety-like behavior during optogenetic stimulation of the mPFC

Two separate experiments were performed to assess the effect of mPFC optogenetic stimulation on measurements of anxiety-like behavior and social memory. Randomly selected C57BL/6J mice receiving the laser stimulations were tested on the elevated plus maze $(n=6$ ChR2mCherry, $n=6$ mCherry), while others ( $n=9$ Chr2-mCherry, $n=9$ mCherry) were examined under the same stimulation conditions during a test for social recognition.

\section{Experiment 5: Validation of optogenetic stimulation of the mPFC via IEG expression}

Verification of cellular activation via optogenetic burst stimulation during behavioral assessments were made by collecting tissue from separate groups of mice, expressing ChR2-mCherry or mCherry, that received 5 min of stimulation. An initial cohort of mice ( $n=4$ ChR2-mCherry, $n=$ $4 \mathrm{mCherry}$ ) were killed $1 \mathrm{~h}$ after stimulation for analysis of c-Fos protein under the infusion site via immunohistochemistry. The number of cells colabeled for c-Fos and ChR $2 / \mathrm{mm}^{2}$, or for c-Fos and mCherry $/ \mathrm{mm}^{2}$, was counted on one brain section for each mouse, where c-Fos was found to be greatest under the stimulation site. In addition, separate groups of mice were optogenetically stimulated and fresh tissue under the stimulation site was collected either $15 \mathrm{~min}(n=5$ ChR2-mCherry, $n=7$ mCherry) or $30 \mathrm{~min}$ ( $n=7$ ChR2-mCherry, $n=7$ mCherry) after stimulation. qPCR was used to assess the expression of zif268, c-fos and $\operatorname{arc}$ mRNA under the site of stimulation.
A

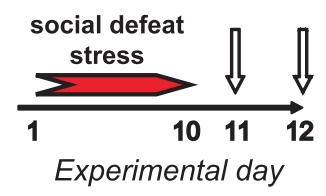

B
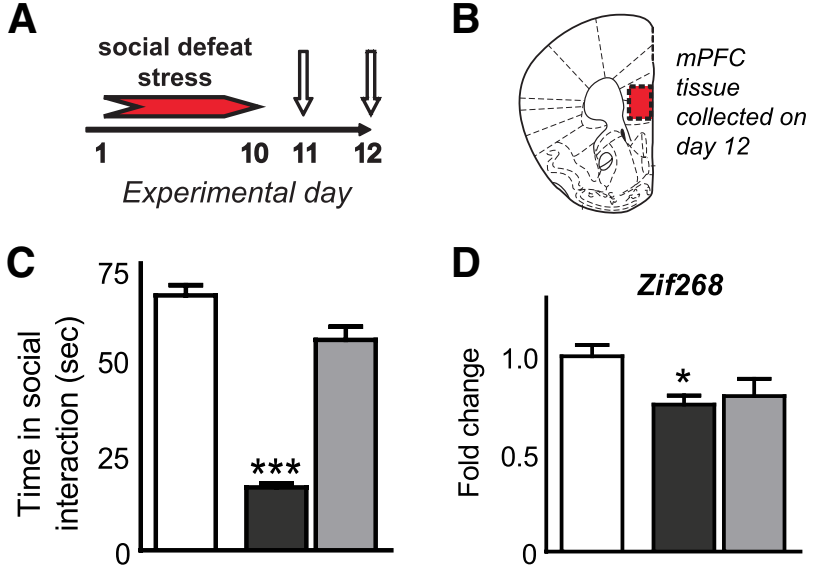

$\mathbf{E}$
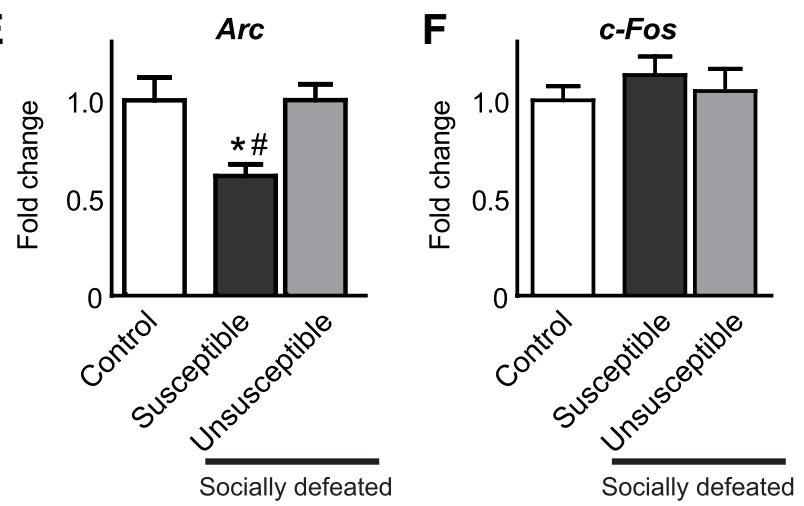

Figure 2. Deficits in IEG expression in mouse mPFC after chronic social defeat stress. zif268, arc and c-fos mRNA expression was quantified via qPCR in tissue collected from mice $48 \mathrm{~h}$ after chronic (10 d) social defeat stress. Twenty-four hours after stress, mice were tested for social interaction to identify susceptible and unsusceptible subgroups ( $\boldsymbol{A}$, first arrow). Twenty-four hours after the social interaction test, tissue from the ventral region of the $\operatorname{mPFC}(\boldsymbol{B})$ was collected for IEG analyses in defeated and control mice ( $\boldsymbol{A}$, second arrow). $\boldsymbol{C}$ shows social interaction scores for susceptible and unsusceptible mice. zif268 and arc, but not $c-f o s$, were reduced in the MPFC of stressed mice, and arc was significantly increased in unsusceptible mice compared with susceptible mice $(\boldsymbol{D}-\boldsymbol{F})$. Significant differences from controls are indicated by ${ }^{*} p<$ 0.05, or $^{* * *} p<0.001$. Significant differences from unsusceptible are indicated by ${ }^{\#} p<0.05$.

\section{Results}

IEG expression in prefrontal cortex of depressed humans and socially defeated mice

Individuals with major depression, compared with matched controls (see supplemental Table, available at www.jneurosci.org as supplemental material), displayed reduced levels of zif268 mRNA in anterior cingulate cortex $\left(F_{(2,21)}=4.9, p=0.02\right)$. This effect was most apparent in subjects who were not on antidepressants at their time of death $(p<0.05$; Fig. $1 B)$; however, a similar trend was observed in medicated depressed cases who nonetheless remained symptomatic despite treatment (as revealed by a $t$ test when both medicated and unmedicated individuals are collapsed and compared with control; $t_{20}=2.23, p=0.01$ ). A similar pattern was seen for $\operatorname{arc}$ mRNA: depressed individuals exhibited reduced levels of arc mRNA compared with controls $\left(F_{(2,21)}=\right.$ 4.9, $p=0.02)$, with a significant reduction in unmedicated depressed cases only ( $p<0.05$; Fig. $1 C)$. A $t$ test did not reveal a significant difference between depressed and controls when both medicated and unmedicated individuals are collapsed; $t_{20}=1.8$, $p=0.08)$. No significant differences were observed in expression levels of $c$-fos mRNA (Fig. 1D).

To further characterize cortical abnormalities in depression, we turned to the chronic social defeat stress model. Chronic (10 
d) social defeat stress in mice induced a severe decrease in social interaction $\left(F_{(2,135)}=211.3, p=0.0001\right)$, as found in earlier studies (Berton et al., 2006; Tsankova et al., 2006). A subset of mice, however, did not exhibit significant social avoidance and were termed unsusceptible, in contrast to the more vulnerable group termed susceptible (Fig. 2C). We have demonstrated previously that this susceptible versus unsusceptible distinction, based on social avoidance scores, is highly predictive of several other deleterious consequences of social defeat stress, including sucrose preference (Krishnan et al., 2007). Similar to IEG data obtained from postmortem depressed human tissue, we found that constitutive levels of zif268 mRNA in mPFC were significantly reduced $\left(F_{(2,23)}=4.9, p=0.03\right.$; Fig. $\left.2 D\right)$ in susceptible mice compared with controls $(p<0.05)$, with a nonsignificant trend seen in unsusceptible animals. arc mRNA levels displayed a similar pattern, with reduced levels seen in the mPFC of susceptible mice $\left(F_{(2,23)}=0.7, p=0.009\right.$; Fig, $2 E$ ), but clearly no effect in unsusceptible mice. No changes were observed in $c$-fos mRNA expression levels in either subgroup (Fig. $2 F$ ). Together, these data are consistent with an overall decrease in neuronal activity in the prefrontal cortex of depressed humans and of susceptible mice after chronic social defeat stress.

\section{Antidepressant-like effect of optogenetic stimulation of mPFC in mice}

To address the behavioral consequences of restoring deficits in prefrontal cortical activity caused by chronic social defeat stress in mice, social interaction was measured during laser stimulation of this brain region in socially defeated and control mice that received local infusion of viral vectors expressing ChR2-mCherry, a light-activated cation channel, or mCherry alone in the mPFC (Fig. $3 A$ ). Susceptible mice that received HSV-ChR2-mCherry exhibited fully restored social interaction scores upon laser stimulation to levels observed in nonstressed controls expressing either ChR2-mCherry or mCherry alone $\left(\operatorname{stress} F_{(1,33)}=6.2, p=0.01\right.$; stimulation $F_{(1,33)}=0.8, p=$ 0.4 ; interaction $\left.F_{(1,33)}=5.3, p=0.03\right)$. In contrast, susceptible mice expressing mCherry alone remained socially avoidant despite laser stimulation (Fig. 3B, top). Moreover, when susceptible mice were retested $24 \mathrm{~h}$ after the initial test session for social interaction without any further laser stimulation, social interaction behavior in ChR2-mCherry-expressing mice was variable and above that of susceptible mice infected with mCherry, but this difference was not significant $\left(t_{(8)}=1.5, p=0.2\right.$; Fig. $3 B$, inset).

Another symptom of clinical depression is a reduced ability to experience pleasure (i.e., anhedonia), which can be measured in chronically stressed rodents by a decrease in their preference for sweet tastes (Keedwell et al., 2005; Krishnan et al., 2007). Indeed, chronic social defeat stress reduced sucrose preference scores in
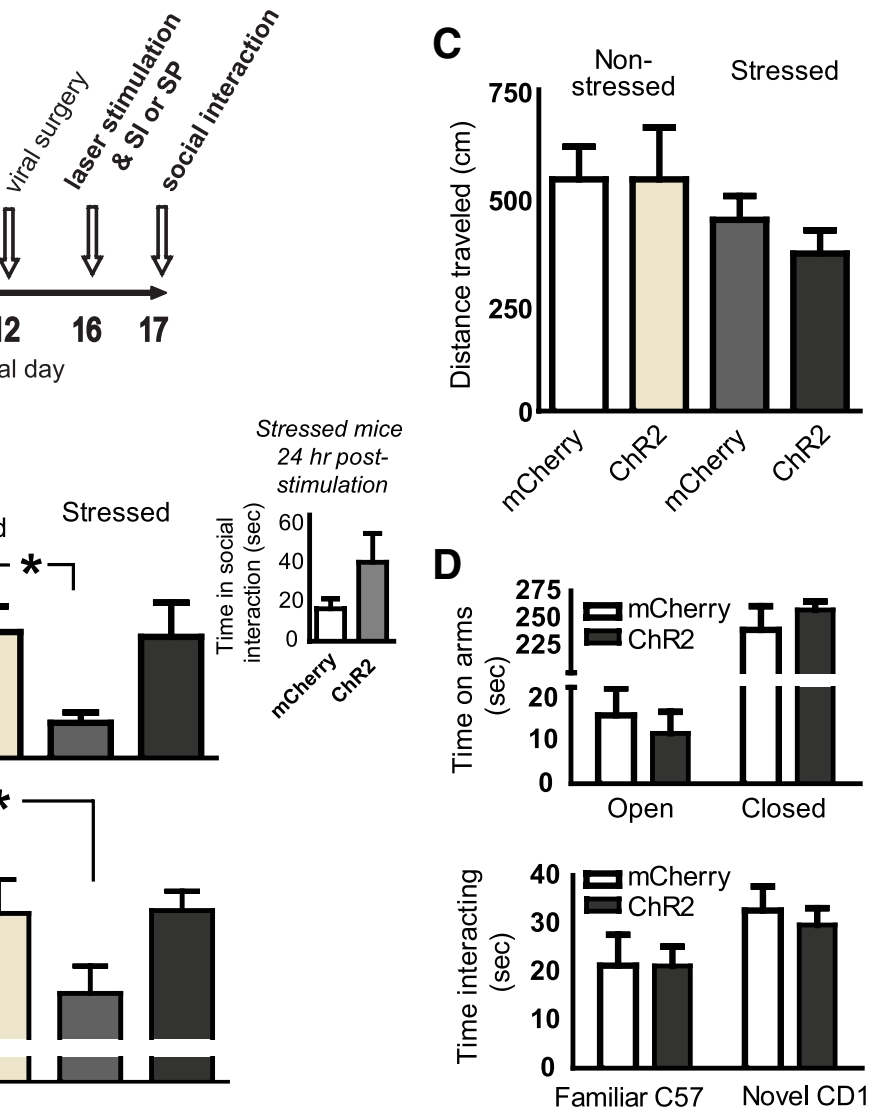

Figure 3. Optogenetic stimulation of mouse mPFC reverses depression-like symptoms induced by chronic social defeat stress. Non-defeated control and socially defeated (susceptible) mice received intra-mPFC injections of viral vectors encoding ChR2列 of social interaction, unlike defeated mice expressing mCherry only ( $\boldsymbol{B}$, top). Despite a trend, this effect is no longer significant $24 \mathrm{~h}$ (a) prevented by $\mathrm{MPF}$ ( stimulation ( $\boldsymbol{B}$, bottom). General locomotor activity in susceptible and control mice was also does not affect anxiety-like behavior as measured in the elevated plus maze (D), or social memory as observed during a social recognition task ( $\boldsymbol{D}$, bottom). Significant differences between bars are indicated by ${ }^{*} p<0.05$.

susceptible mice, an effect not seen in unsusceptible mice, as reported previously (Krishnan et al., 2007). Moreover, ChR2mediated stimulation of the mPFC of susceptible mice prevented a significant reduction of sucrose preference seen in susceptible mice expressing mCherry alone, as indicated by an interaction between stress and stimulation $\left(F_{(1,22)}=4.6, p=0.04\right.$; Fig. $3 B$, bottom). These robust antidepressant-like effects observed during cortical stimulation were not associated with a change in anxiety-like behavior, as reflected by general locomotor activity during an open field test (Fig. 3C) or when mice were analyzed on an elevated plus maze test (Fig. 3D, top). Furthermore, stimulation of the mPFC did not alter social memory, based on a test for social recognition (Fig. 3D, bottom).

To validate that optogenetic stimulation of mouse mPFC successfully increased neuronal activity within this brain region, we assessed IEG expression in this brain region (Fig. 4). We found a robust and significant increase in the number of cells colabeled for c-Fos protein and ChR2-mCherry, but not for c-Fos protein alone, in response to a burst pattern of laser stimulation $\left(t_{6}=7.6\right.$, $p=0.0003$, data not shown) when compared with laser stimula- 
A

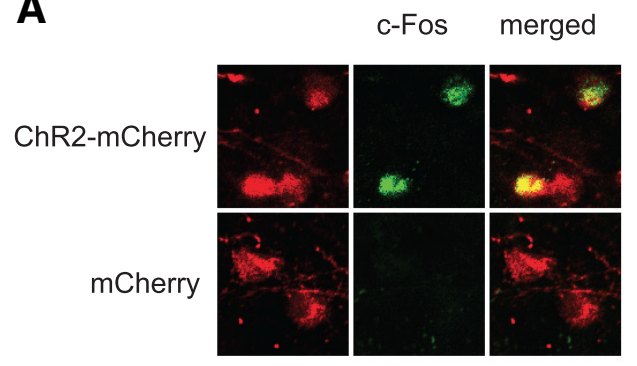

C IEG expression 15 min after stimulation

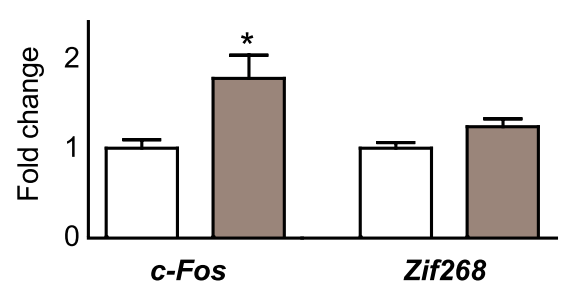

D IEG expression 30 min after stimulation

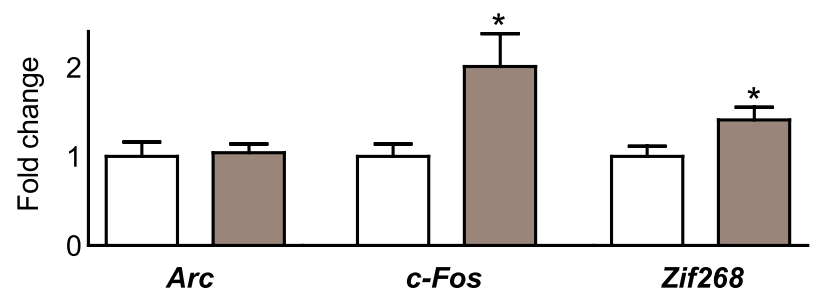

Figure 4. Optogenetic stimulation of the mPFC increases immediate early gene expression. $A-D$, Laser stimulation induces c-Fos protein specifically in cells that express ChR2 (A). Stimulation-induced c-Fos expression occurs in cells colabeled for CaMKII (i.e., excitatory pyramidal neurons) or GABA (i.e., inhibitory interneurons) (B). Burst patterns of stimulation in the $\mathrm{mPFC}$, after viral expression of ChR2-mCherry, but not mCherry alone, increases cellular measures of functional activity as measured by mRNA expression of $\mathrm{c}$-fos within $15 \mathrm{~min}$ of stimulation (C), and both c-fos and zif268, but not arc, within 30 min of stimulation (D). Significant differences between bars are indicated by ${ }^{*} p<0.05$.

tion in mice expressing mCherry alone. In addition, we observed that c-Fos expression was robust over a $\sim 1 \mathrm{~mm}$ area of the $\mathrm{mPFC}$ just below the placement of the optical fiber. mRNA levels of $c$-fos $\left(t_{10}=3.2, p=0.01\right)$, which is not constitutively expressed, were increased in the mPFC within 15 min after laser stimulation in animals injected with HSV-ChR2-mCherry, but not HSVmCherry (Fig. 4A). Double immunolabeling experiments demonstrated that such c-Fos induction occurred both in excitatory pyramidal neurons (marked by CaMKII) and in GABAergic interneurons (marked by GABA) (Fig. 4B), consistent with the known ability of HSV vectors to infect all neurons (Neve et al., 2005). Likewise, in those mice expressing ChR2-mCherry, mRNA levels of both $c$-fos $\left(t_{12}=2.6, p=0.03\right)$ and zif268 $\left(t_{12}=2.3, p=0.04\right)$ were increased within 15-30 min after laser stimulation (Fig. 4C,D); however, $\operatorname{arc}$ mRNA levels were not affected at this time point.

\section{Discussion}

Adaptations in the prefrontal cortex, as inferred from imaging studies in humans or IEG expression in rodents, have been linked to changes in emotional responses and reward-based decision making (Kuipers et al., 2003; Thomas et al., 2003; Tanis et al., 2008; Banasr and Duman, 2008; Dias-Ferreira et al., 2009; Hains et al., 2009). In line with these earlier studies, the current results reveal that, in the human anterior cingulate cortex, zif268 and arc mRNA expression is downregulated in clinically depressed sub- jects. In parallel, we found that chronic social defeat stress in mice causes decreased levels of zif268 and arc mRNA in the ventral mPFC, one of several regions of prefrontal cortex that show some functional homology with the human anterior cingulate cortex (Vertes, 2006). These IEG effects predominated in susceptible, but not unsusceptible, animals. These findings further validate this rodent model of depression. The observed deficits in IEG expression, which are markers of neuronal activity, suggest that impaired cortical activity, such as reductions in burst firing patterns in the mPFC (Ono et al., 1984; Baeg et al., 2001), may contribute to the emergence of emotional disturbances. Indeed, we found that mimicking a burstlike pattern of cortical activity using in vivo optogenetic stimulation induced potent antidepressant-like responses, including restoration of social interaction and sucrose preference, in susceptible mice after chronic social defeat stress. These antidepressant-like effects of optogenetic stimulation did not disrupt other behaviors, such as general locomotor activity, anxiety-like responses, and social memory. The data suggest that activation of the mPFC leads to immediate changes in brain circuits that correct behavioral deficits associated with social defeat. While further work is needed to understand the nature of these circuit-level changes, our findings indicate that experimental treatments, which enhance overall activity selectively in the prefrontal cortex, may be of great therapeutic benefit for mood disorders.

\section{IEG expression in the MPFC and depression}

Several points should be highlighted regarding the regulation of IEG expression in the prefrontal cortex of both clinically depressed humans and mice following chronic social defeat stress. First, decreases in cortical zif268 and arc expression in clinically depressed subjects is particularly interesting in light of the persistent cognitive deficits associated with this illness. zif268 and arc are strongly activated in brain areas important for conditioned behaviors, therefore, decreased expression of these genes in prefrontal cortex may reflect deficits in the ability to encode new experiences (Herry and Mons, 2004; Durstewitz et al., 2010; Rapanelli et al., 2010). Given that optogenetic stimulation increases zif268, but not arc, expression, further demonstrates the complexity of arc transcription, a process that may be context dependent, requiring the orchestration of numerous cellular events, including extracellular signal-regulated kinase, protein kinase A, and protein kinase C signaling (Waltereit et al., 2001; Teber et al., 2004), which may not be triggered through our stimulation parameters. The lack of augmented arc expression via optogenetic stimulation might contribute to the lack of persistence of a clear antidepressant-like effect in mice tested $24 \mathrm{~h}$ after stimulation. Conversely, unsusceptible mice display significantly higher levels of arc expression compared with susceptible mice, 
again suggesting that this IEG within prefrontal cortical regions may be critically involved in coping with stress. Similarly, restoring constitutive levels of functional activity may be a necessary requirement of antidepressant action in humans. For example, the lack of significant reversal of decreased arc and zif268 expression by antidepressant medication in clinically depressed subjects may aid in explaining why these individuals remained symptomatic, and why direct stimulation of prefrontal cortex has been effective in a large subset of treatment-resistant patients (e.g., Mayberg et al., 2005).

Expression of zif268 in rodent $\mathrm{mPFC}$ has recently been positively correlated with social behavior (Stack et al., 2010). Thus, stress-induced decreases in zif268 expression that we observe in this region may directly contribute to the lack of social interaction observed in our studies. Likewise, the rapid increase in this IEG upon acute optogenetic stimulation may reflect the rapid antidepressant-like effects observed herein. As expected, because $c$-fos is constitutively expressed at very low levels in adult brain (Dragunow and Faull, 1989), we did not observe basal changes in expression of this IEG in clinically depressed prefrontal tissue, or after chronic social stress in mice. However, in line with this IEG's stimulus-dependent pattern of expression, $c$-fos was rapidly induced in $\mathrm{mPFC}$ in response to optogenetic stimulation, further verifying activation of this neural circuit.

\section{Antidepressant-like effects of optogenetic stimulation of the mPFC}

The $100 \mathrm{~Hz}$ stimulation protocol used in these studies may have been critical for observing antidepressant-like effects following stress. Brain stimulation of $>100 \mathrm{~Hz}$ has been reported to be more effective in producing antidepressant-like effects both in clinical studies and in rodent models where sucrose preferences were measured (Mayberg et al., 2005; Hamani et al., 2010a,b). Although optogenetic stimulation via the aforementioned stimulation conditions in the mPFC is limited to a very small volume of tissue, Deisseroth and colleagues have consistently reported power densities of $1-10 \mathrm{~mW} / \mathrm{mm}^{2}$ being suitable for optogenetic control, and our stimulations were within this range. In addition, a $100 \mathrm{~Hz}$ peak in the spiking power spectrum of subthalamic neurons has been reported using ChR2 (Tsai et al., 2009). While many cells infected with ChR2 may not be directly activated by the blue light at $100 \mathrm{~Hz}$, the entire circuit is likely being influenced by the stimulation, as evidenced by a twofold induction of $c$-fos expression in grossly dissected mPFC tissue, due to the large number of local connections in the mPFC (Houser et al., 1985; Rétaux et al., 1992). It will be important in future studies to verify the pattern of neuronal firing induced in $\mathrm{mPFC}$ upon optogenetic stimulation, as well as to characterize various stimulation parameters (e.g., frequency, duration, pattern) for their antidepressant potential.

The ventral portion of rodent $\mathrm{mPFC}$ contains both infralimbic and prelimbic subdivisions (Groenewegen et al., 1990; Tzschentke and Schmidt, 2000; Vertes, 2006). Likewise, the mPFC consists of a heterogeneous collection of neurons, including excitatory pyramidal neurons and local GABAergic interneurons (Steketee, 2005). Our stimulation conditions are likely to be activating much of the ventral portion of the $\mathrm{mPFC}$ based on IEG expression patterns. The viral vector used in our study, while neuron-specific, does not distinguish between these neuronal cell types (Neve et al., 2005). This was confirmed by our double immunolabeling experiments, which showed that both excitatory and inhibitory neurons within the mPFC exhibited c-Fos induction following optogenetic stimulation. Hence, we do not know whether the optogenetic activation of the tissue produces a net increase or decrease in the output of this circuit. While future studies are needed to directly address the role of particular prefrontal cortical cells in antidepressant-like responses, we hypothesize that the optogenetic stimulation of mPFC used here increases the firing of descending projection neurons that target other limbic brain regions as well as subcortical monoaminergic nuclei. This hypothesis is derived, in part, from brain stimulation studies in rat where lesions that deplete serotonin diminish the antidepressant-like effects of mPFC stimulation (Hamani et al., 2010a).

\section{Conclusions}

In summary, this study extends recent clinical findings, which demonstrate that brain stimulation within the prefrontal cortex can be effective for severe treatment-resistant depression (Lozano et al., 2008; Giacobbe et al., 2009; Malone et al., 2009; Bewernick et al., 2010). We hypothesize that particular prefrontal projections are altered in response to chronic social stress, and that targeting such projections in future optogenetic studies will provide critical insight into their role in the development of depressive-like behaviors. For example, as electrophysiological data discerning specific patterns of normal cortical activity become available, it will become feasible to induce a particular pattern of activity (e.g., via optogenetic activation, direct brain stimulation, or pharmacological manipulation) to eliminate certain behavioral disturbances manifested during the course of clinical depression (e.g., anhedonia, social withdrawal, etc.). Such experiments are now feasible given the recent development of optogenetic tools for activating, or inactivating, specific projection neurons (Gradinaru et al., 2010). Together, our data suggest that deficits in the functional activity of the prefrontal cortex play a causal role in depression-related behavioral disturbances, helping to resolve arguments concerning the cause-consequence of cortical activity occurring prior, or subsequent, to the onset of depression.

\section{References}

Adamantidis AR, Zhang F, Aravanis AM, Deisseroth K, de Lecea L (2007) Neural substrates of awakening probed with optogenetic control of hypocretin neurons. Nature 450:420-424.

Airan RD, Thompson KR, Fenno LE, Bernstein H, Deisseroth K (2009) Temporally precise in vivo control of intracellular signalling. Nature 458:1025-1029.

Baeg EH, Kim YB, Jang J, Kim HT, Mook-Jung I, Jung MW (2001) Fast spiking and regular spiking neural correlates of fear conditioning in the medial prefrontal cortex of the rat. Cereb Cortex 11:441-451.

Banasr M, Duman RS (2008) Glial loss in the prefrontal cortex is sufficient to induce depressive-like behaviors. Biol Psychiatry 64:863-870.

Barbas H (1995) Anatomic basis of cognitive-emotional interactions in the primate prefrontal cortex. Neurosci Biobehav Rev 19:499-510.

Berton O, McClung CA, Dileone RJ, Krishnan V, Renthal W, Russo SJ, Graham D, Tsankova NM, Bolanos CA, Rios M, Monteggia LM, Self DW, Nestler EJ (2006) Essential role of BDNF in the mesolimbic dopamine pathway in social defeat stress. Science 311:864-868.

Bewernick BH, Hurlemann R, Matusch A, Kayser S, Grubert C, Hadrysiewicz B, Axmacher N, Lemke M, Cooper-Mahkorn D, Cohen MX, Brockmann H, Lenartz D, Sturm V, Schlaepfer TE (2010) Nucleus accumbens deep brain stimulation decreases ratings of depression and anxiety in treatment-resistant depression. Biol Psychiatry 67:110-116.

Bramham CR, Worley PF, Moore MJ, Guzowski JF (2008) The immediate early gene arc/arg3.1: regulation, mechanisms, and function. J Neurosci 28:11760-11767.

Covington HE 3rd, Kikusui T, Goodhue J, Nikulina EM, Hammer RP Jr, Miczek KA (2005) Brief social defeat stress: long lasting effects on cocaine taking during a binge and zif268 mRNA expression in the amygdala and prefrontal cortex. Neuropsychopharmacology 30:310-321. 
Covington HE 3rd, Maze I, LaPlant QC, Vialou VF, Ohnishi YN, Berton O, Fass DM, Renthal W, Rush AJ 3rd, Wu EY, Ghose S, Krishnan V, Russo SJ, Tamminga C, Haggarty SJ, Nestler EJ (2009) Antidepressant actions of histone deacetylase inhibitors. J Neurosci 29:11451-11460.

Czéh B, Müller-Keuker JI, Rygula R, Abumaria N, Hiemke C, Domenici E, Fuchs E (2007) Chronic social stress inhibits cell proliferation in the adult medial prefrontal cortex: hemispheric asymmetry and reversal by fluoxetine treatment. Neuropsychopharmacology 32:1490-1503.

Dias-Ferreira E, Sousa JC, Melo I, Morgado P, Mesquita AR, Cerqueira JJ, Costa RM, Sousa N (2009) Chronic stress causes frontostriatal reorganization and affects decision-making. Science 325:621-625.

Diorio D, Viau V, Meaney MJ (1993) The role of the medial prefrontal cortex (cingulate gyrus) in the regulation of hypothalamic-pituitaryadrenal responses to stress. J Neurosci 13:3839-3847.

Dluzen DE, Kreutzberg JD (1993) 1-Methyl-4-phenyl-1,2,3,6-tetrahydropyridine (MPTP) disrupts social memory/recognition processes in the male mouse. Brain Res 609:98-102.

Dragunow M (1996) A role for immediate-early transcription factors in learning and memory. Behav Genet 26:293-299.

Dragunow M, Faull R (1989) The use of c-fos as a metabolic marker in neuronal pathway tracing. J Neurosci Methods 29:261-265.

Durstewitz D, Vittoz NM, Floresco SB, Seamans JK (2010) Abrupt transitions between prefrontal neural ensemble states accompany behavioral transitions during rule learning. Neuron 66:438-448.

Fales CL, Barch DM, Rundle MM, Mintun MA, Snyder AZ, Cohen JD, Mathews J, Sheline YI (2008) Altered emotional interference processing in affective and cognitive-control brain circuitry in major depression. Biol Psychiatry 63:377-384.

Giacobbe P, Mayberg HS, Lozano AM (2009) Treatment resistant depression as a failure of brain homeostatic mechanisms: implications for deep brain stimulation. Exp Neurol 219:44-52.

Gradinaru V, Thompson KR, Zhang F, Mogri M, Kay K, Schneider MB, Deisseroth K (2007) Targeting and readout strategies for fast optical neural control in vitro and in vivo. J Neurosci 27:14231-14238.

Gradinaru V, Zhang F, Ramakrishnan C, Mattis J, Prakash R, Diester I, Goshen I, Thompson KR, Deisseroth K (2010) Molecular and cellular approaches for diversifying and extending optogenetics. Cell 141:154-165.

Groenewegen HJ, Berendse HW, Wolters JG, Lohman AH 1990 The anatomical relationship of the prefrontal cortex with the striatopallidal system, the thalamus and the amygdala: evidence for a parallel organization. Prog Brain Res 85:95-116.

Hains AB, Vu MA, Maciejewski PK, van Dyck CH, Gottron M, Arnsten AF (2009) Inhibition of protein kinase $C$ signaling protects prefrontal cortex dendritic spines and cognition from the effects of chronic stress. Proc Natl Acad Sci U S A 106:17957-17962.

Hamani C, Diwan M, Macedo CE, Brandão ML, Shumake J, Gonzalez-Lima F, Raymond R, Lozano AM, Fletcher PJ, Nobrega JN (2010a) Antidepressantlike effects of medial prefrontal cortex deep brain stimulation in rats. Biol Psychiatry 67:117-124.

Hamani C, Diwan M, Isabella S, Lozano AM, Nobrega JN (2010b) Effects of different stimulation parameters on the antidepressant-like response of medial prefrontal cortex deep brain stimulation in rats. J Psychiatr Res 44:683-687.

Heidbreder CA, Groenewegen HJ (2003) The medial prefrontal cortex in the rat: evidence for a dorso-ventral distinction based upon functional and anatomical characteristics. Neurosci Biobehav Rev 27:555-579.

Herry C, Mons N (2004) Resistance to extinction is associated with impaired immediate early gene induction in medial prefrontal cortex and amygdala. Eur J Neurosci 20:781-790.

Holson RR (1986) Mesial prefrontal cortical lesions and timidity in rats. III. Behavior in a semi-natural environment. Physiol Behav 37:239-247.

Houser CR, Crawford GD, Salvaterra PM, Vaughn JE (1985) Immunocytochemical localization of choline acetyltransferase in rat cerebral cortex: a study of cholinergic neurons and synapses. J Comp Neurol 234:17-34.

Keedwell PA, Andrew C, Williams SC, Brammer MJ, Phillips ML (2005) The neural correlates of anhedonia in major depressive disorder. Biol Psychiatry 58:843-853.

Krishnan V, Nestler EJ (2008) Molecular neurobiology of depression. Nature 455:894-902.

Krishnan V, Han MH, Graham DL, Berton O, Renthal W, Russo SJ, Laplant Q, Graham A, Lutter M, Lagace DC, Ghose S, Reister R, Tannous P, Green TA, Neve RL, Chakravarty S, Kumar A, Eisch AJ, Self DW, Lee FS, et al
(2007) Molecular adaptations underlying susceptibility and resistance to social defeat in brain reward regions. Cell 131:391-404.

Kuipers SD, Trentani A, Den Boer JA, Ter Horst GJ (2003) Molecular correlates of impaired prefrontal plasticity in response to chronic stress. J Neurochem 85:1312-1323.

Liston C, Miller MM, Goldwater DS, Radley JJ, Rocher AB, Hof PR, Morrison JH, McEwen BS (2006) Stress-induced alterations in prefrontal cortical dendritic morphology predict selective impairments in perceptual attentional set-shifting. J Neurosci 26:7870-7874.

Lobo MK, Covington HE III, Chaudhury D, Friedman AK, Sun HS, DamezWerno D, Dietz D, Zaman S, Koo JW, Kennedy PJ, Mouzon E, Mogri M, Neve RL, Deisseroth K, Han MH, Nestler EJ (2010) Cell type specific loss of BDNF signaling mimics optogenetic control of cocaine reward. Science 330:385-390.

Lozano AM, Mayberg HS, Giacobbe P, Hamani C, Craddock RC, Kennedy SH (2008) Subcallosal cingulate gyrus deep brain stimulation for treatment-resistant depression. Biol Psychiatry 64:461-467.

Malone DA Jr, Dougherty DD, Rezai AR, Carpenter LL, Friehs GM, Eskandar EN, Rauch SL, Rasmussen SA, Machado AG, Kubu CS, Tyrka AR, Price LH, Stypulkowski PH, Giftakis JE, Rise MT, Malloy PF, Salloway SP, Greenberg BD (2009) Deep brain stimulation of the ventral capsule/ ventral striatum for treatment-resistant depression. Biol Psychiatry 65:267-275.

Manji HK, Drevets WC, Charney DS (2001) The cellular neurobiology of depression. Nat Med 7:541-547.

Mayberg HS (2003) Modulating dysfunctional limbic-cortical circuits in depression: towards development of brain-based algorithms for diagnosis and optimised treatment. Br Med Bull 65:193-207.

Mayberg HS, Lozano AM, Voon V, McNeely HE, Seminowicz D, Hamani C, Schwalb JM, Kennedy SH (2005) Deep brain stimulation for treatmentresistant depression. Neuron 45:651-660.

Maze I, Covington HE 3rd, Dietz DM, LaPlant Q, Renthal W, Russo SJ, Mechanic M, Mouzon E, Neve RL, Haggarty SJ, Ren Y, Sampath SC, Hurd YL, Greengard P, Tarakhovsky A, Schaefer A, Nestler EJ (2010) Essential role of the histone methyltransferase G9a in cocaine-induced plasticity. Science 327:213-216.

Milad MR, Quirk GJ (2002) Neurons in medial prefrontal cortex signal memory for fear extinction. Nature 420:70-74.

Monteggia LM, Luikart B, Barrot M, Theobold D, Malkovska I, Nef S, Parada LF, Nestler EJ (2007) Brain-derived neurotrophic factor conditional knockouts show gender differences in depression-related behaviors. Biol Psychiatry 61:187-197.

Nahas Z, Anderson BS, Borckardt J, Arana AB, George MS, Reeves ST, Takacs I (2010) Bilateral epidural prefrontal cortical stimulation for treatmentresistant depression. Biol Psychiatry 67:101-109.

Neve RL, Neve KA, Nestler EJ, Carlezon WA Jr (2005) Use of herpes virus amplicon vectors to study brain disorders. Biotechniques 39:381-391.

Nikulina EM, Covington HE 3rd, Ganschow L, Hammer RP Jr, Miczek KA (2004) Long-term behavioral and neuronal cross-sensitization to amphetamine induced by repeated brief social defeat stress: Fos in the ventral tegmental area and amygdala. Neuroscience 123:857-865.

Ono T, Nishino H, Fukuda M, Sasaki K, Nishijo H (1984) Single neuron activity in dorsolateral prefrontal cortex of monkey during operant behavior sustained by food reward. Brain Res 311:323-332.

Radley JJ, Rocher AB, Rodriguez A, Ehlenberger DB, Dammann M, McEwen BS, Morrison JH, Wearne SL, Hof PR (2008) Repeated stress alters dendritic spine morphology in the rat medial prefrontal cortex. J Comp Neurol 507:1141-1150.

Rapanelli M, Lew SE, Frick LR, Zanutto BS (2010) Plasticity in the rat prefrontal cortex: linking gene expression and an operant learning with a computational theory. PLoS One 5:e8656.

Renthal W, Maze I, Krishnan V, Covington HE 3rd, Xiao G, Kumar A, Russo SJ, Graham A, Tsankova N, Kippin TE, Kerstetter KA, Neve RL, Haggarty SJ, McKinsey TA, Bassel-Duby R, Olson EN, Nestler EJ (2007) Histone deacetylase 5 epigenetically controls behavioral adaptations to chronic emotional stimuli. Neuron 56:517-529.

Rétaux S, Julien JF, Besson MJ, Penit-Soria J (1992) Expression of GAD mRNA in GABA interneurons of the rat medial frontal cortex. Neurosci Lett 136:67-71.

Rygula R, Abumaria N, Havemann-Reinecke U, Rüther E, Hiemke C, Zernig G, Fuchs E, Flügge G (2008) Pharmacological validation of a chronic 
social stress model of depression in rats: effects of reboxetine, haloperidol and diazepam. Behav Pharmacol 19:183-196.

Silva MG, Boyle MA, Finger S, Numan B, Bouzrara AA, Almli CR (1986) Behavioral effects of large and small lesions of the rat medial frontal cortex. Exp Brain Res 65:176-181.

Stack A, Carrier N, Dietz D, Hollis F, Sorenson J, Kabbaj M (2010) Sex differences in social interaction in rats: role of the immediate-early gene zif268. Neuropsychopharmacology 35:570-580.

Stan AD, Ghose S, Gao XM, Roberts RC, Lewis-Amezcua K, Hatanpaa KJ, Tamminga CA (2006) Human postmortem tissue: what quality markers matter? Brain Res 1123:1-11.

Steketee JD (2005) Cortical mechanisms of cocaine sensitization. Crit Rev Neurobiol 17:69-86.

Tanis KQ, Duman RS, Newton SS (2008) CREB binding and activity in brain: regional specificity and induction by electroconvulsive seizure. Biol Psychiatry 63:710-720.

Teber I, Köhling R, Speckmann EJ, Barnekow A, Kremerskothen J (2004) Muscarinic acetylcholine receptor stimulation induces expression of the activity-regulated cytoskeleton-associated gene (ARC). Brain Res Mol Brain Res 121:131-136.

Thomas KL, Arroyo M, Everitt BJ (2003) Induction of the learning and plasticity-associated gene Zif268 following exposure to a discrete cocaineassociated stimulus. Eur J Neurosci 17:1964-1972.

Tsai HC, Zhang F, Adamantidis A, Stuber GD, Bonci A, de Lecea L, Deisseroth
K (2009) Phasic firing in dopaminergic neurons is sufficient for behavioral conditioning. Science 324:1080-1084.

Tsankova NM, Berton O, Renthal W, Kumar A, Neve RL, Nestler EJ (2006) Sustained hippocampal chromatin regulation in a mouse model of depression and antidepressant action. Nat Neurosci 9:519-525.

Tzschentke TM, Schmidt WJ (2000) Functional relationship among medial prefrontal cortex, nucleus accumbens, and ventral tegmental area in locomotion and reward. Crit Rev Neurobiol 14:131-142.

Vertes RP (2006) Interactions among the medial prefrontal cortex, hippocampus and midline thalamus in emotional and cognitive processing in the rat. Neuroscience 142:1-20.

Vogt BA, Finch DM, Olson CR (1992) Functional heterogeneity in cingulate cortex: the anterior executive and posterior evaluative regions. Cereb Cortex 2:435-443.

Waltereit R, Dammermann B, Wulff P, Scafidi J, Staubli U, Kauselmann G, Bundman M, Kuhl D (2001) Arg3.1/Arc mRNA induction by $\mathrm{Ca}^{2+}$ and cAMP requires protein kinase $\mathrm{A}$ and mitogen-activated protein kinase/ extracellular regulated kinase activation. J Neurosci 21:5484-5493.

Yang CR, Seamans JK, Gorelova N (1996) Electrophysiological and morphological properties of layers V-VI principal pyramidal cells in rat prefrontal cortex in vitro. J Neurosci 16:1904-1921.

Zhang F, Wang LP, Brauner M, Liewald JF, Kay K, Watzke N, Wood PG, Bamberg E, Nagel G, Gottschalk A, Deisseroth K (2007) Multimodal fast optical interrogation of neural circuitry. Nature 446:633-639. 